\section{JMLE \\ JOURNAL OF MEDIA LITERACY EDUCATION}

\title{
Piloting journalistic learning in a rural Trump-supportive community: A reverse mentorship approach
}

\author{
Ed Madison \\ University of Oregon
}

\section{OPEN ACCESS}

Peer-reviewed article

Citation: Madison, E. (2019). Piloting journalistic learning in a rural Trump-supportive community: A reverse mentorship approach. Journal of Media Literacy Education, 11(3), 49-60. doi: 10.23860/JMLE-2019-113-5

\section{Corresponding Author:}

Ed L. Madison

madison2@uoregon.edu

Copyright: () 2019 Author(s). This is an open access, peer-reviewed article edited by NAMLE, published by Bepress and distributed under the terms of the Creative Commons Attribution License, which permits unrestricted use, distribution, and reproduction in any medium, provided the original author and source are credited.

Received: September 11, 2017

Accepted: May 15, 2019

Published: November 30, 2019

Data Availability Statement: All relevant data are within the paper and its Supporting Information files.

Competing Interests: The Author(s) declare(s) no conflict of interest.

\section{$\underline{\text { Editorial Board }}$}

\begin{abstract}
Partisan politics challenge educators to determine how best to navigate discussions of controversial subjects within their classrooms. This can be particularly true for new educators in the early stages of developing their confidence and classroom management skills. This qualitative case study uses situated learning and the communities of practice theoretical constructs to investigate a new approach to educator training and co-facilitation. The new approach places recent journalism school college graduates in classrooms alongside teachers to foster real-time professional development through a process best described as reverse mentoring. The model could potentially provide educators with new pedagogical strategies during divisive political times. Specifically, this study examines the working relationship between an established sixth grade English-language arts/social studies teacher and a 25year-old recent journalism school college graduate who collaborated during the 2016-17 academic year at a public middle school in a conservative rural community in the Pacific Northwest.
\end{abstract}

Keywords: situated learning, journalistic learning, media literacy education, reverse mentoring, Trump.

\section{Journal of Media Literacy Education}

THE OFFICIAL PUBLICATION OF THE

National AsSOCiation for MEdia literacy Education (NAMLE)

Online at www.jmle.org 


\section{INTRODUCTION}

The controversies surrounding the election of President Donald J. Trump can widen ideological divides and thrust educators into uncharted territory. This can especially be the case when teaching a course with a curricular emphasis on media literacy, and specifically journalism, given that the profession itself has recently been the subject of much debate. Partisan politics challenge educators to determine how best to navigate discussions of controversial subjects within their classrooms. This can alarm new teachers in the early stages of developing confidence and classroom management skills. Concerns are wide-ranging. How do you create a classroom environment that is inclusive of opposing viewpoints? What is the appropriate amount of personal sharing when it comes to political views? And what sensitivities should you consider when views expressed in your classroom may contradict the perspectives students encounter from parents at home?

This qualitative case study investigates our research team's development of the Journalistic Learning Initiative (JLI), a program that incorporates a new approach to educator training, which was piloted at a public middle school set in a conservative rural community in the Pacific Northwest. JLI uses journalism education strategies to enhance learning outcomes, with the program embedded in secondary English language arts and social studies courses. The approach acknowledges and honors students' intrinsic interests as a first step before introducing more challenging themes - thereby meeting students where they are (Madison, 2012, 2015).

JLI's methods draw from a four-part framework (see Figure 1) that emphasizes voice, agency, publication and reflection. Voice supports students in realizing that their opinions and experiences matter; agency has them see that their voice can influence others; publication acknowledges the power of sharing their stories with an authentic audience - not just teachers; and reflection completes the process by having students broaden their awareness and explore deeper meanings. The JLI Core Framework aligns with situated learning (Lave \& Wenger, 1991) and communities of practice (Wenger, 1998), the theoretical constructs used to examine this case. This study's focus is on a co-facilitation element of the program that places recent journalism school (college) graduates in classrooms to work alongside teachers to enhance media literacy and foster real-time professional development, through a process best described as reverse mentoring.

\section{JLI CORE FRAMEWORK}

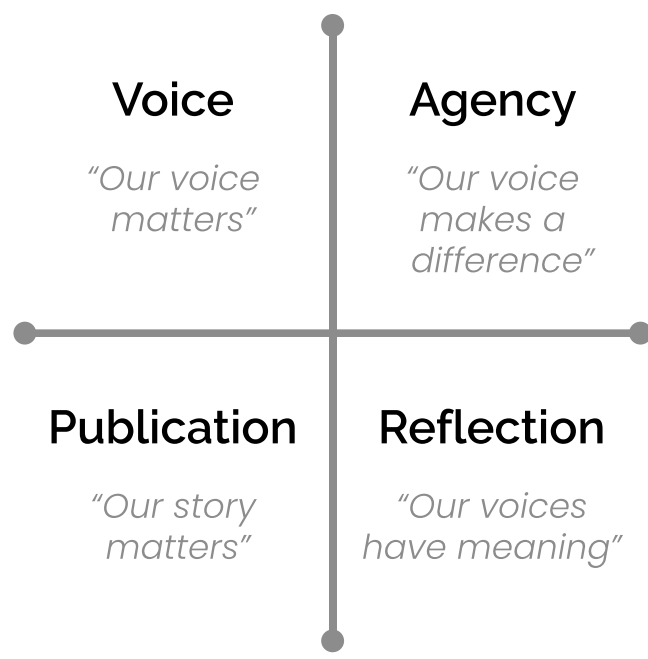

JLI empowers students' IDENTITY and VOICE, which is essential to learning and life skills

Q2018 JV

Figure 1. JLI core framework. This figure illustrates the four-part framework that informs JLI methods

The term and approach are attributed to former General Electric CEO Jack Welch, who in 1999 recruited a team of young associates to educate 500 of his senior executives, who had limited knowledge of how to maximize the internet's potential (Steimle, 2015). It is a practice that remains prevalent at tech companies like Cisco and Hewlett Packard. However, this specific approach is nearly nonexistent in K-12 teacher training literature. When applied in education, the objective of reverse mentoring is to contemporize the classroom experience and enhance learning outcomes. The notion of systematically assigning millennials to mentor teachers may seem antithetical within the context of how teacher training and professional development are traditionally viewed. However, conceptually, reverse mentors can bring fresh perspectives, multimedia journalism instructional skills, and technology support into classrooms where they may be otherwise missing.

Implementation of new initiatives can be viewed with suspicion in conservative communities, given that the journalism practice was significantly politicized during the lead-up to and in the aftermath of the 2016 presidential election. This exploratory study examines the working relationship between an established sixth grade English-Language Arts/social studies teacher and a 25-year-old recent journalism school graduate who 
collaborated during the 2016-17 academic year at a public middle school located in a rural community in the Pacific Northwest. Field observation, interviews, and work-related artifacts provided data for this investigation.

\section{LITERATURE REVIEW}

\section{Media Literacy and Journalism Education}

Media literacy and journalism education strengthen students' ability to read, write, and research - largely because these practices contribute to and cultivate critical thinking (Hobbs, 2007; Madison, 2012, 2015; Morrell, 2004). Numerous studies show that students who have high school publication experience earn better grades and test scores in high school and college. Dvorak and Choi's (2009) study of 30,000 students' ACT test results revealed that those who worked at high school papers or on yearbook staffs performed better than peers in seventeen significant areas of academic achievement. They also analyzed a subset of the data, focusing on minorities, which addressed journalism's prospective ability to impact the achievement gap. Minorities with student high school publication experience outperformed minority students without it in twelve out of fifteen major academic comparisons (Dvorak, Bowen, \& Choi, 2009). Two decades earlier, Dvorak (1988) found that college freshmen with prior high school publication experience had higher writing scores than non-publication peers in thirteen out of sixteen writing sample comparisons. Blinn (1982) compared advanced placement English and senior honors students with journalism students and revealed that journalism writers made fewer errors.

\section{Teaching Controversial Issues}

Few will deny the educational value of breaking political news. "Students with higher levels of civic knowledge are more likely to expect to participate in political and civic activities as adults" (Kerr, Lines, Blenkinsop, \& Schagen, 2003, p. 4). Yet controversial topics by nature can be contentious and emotionally charged. Educators who lack experience with engaging students in sensitive topics may fear professional repercussions from allowing students to pursue certain areas of discussion. Another potential concern is that political discussions may delve into areas parents deem inappropriate or that conflict with family beliefs.
A cross-section of scholarly literature on the topic of teaching controversial subjects reveals a robust and contentious debate. Stradling (1985) defines controversial issues as "those issues on which our society is clearly divided and significant groups within society advocate conflicting explanations or solutions based on alternative values" (p. 9). However, as Oulton and colleagues emphasize, the very idea of discussing, let alone teaching, a controversial topic becomes controversial (Oulton, Day, Dillon, \& Grace, 2004). This presents a Catch-22 for educators, who run the risk of appearing biased or even reckless when attempting to teach the merits of diverse perspectives. In England, and other countries, "teaching the nature of controversy" is considered essential to better prepare students to engage with real world matters However, teachers continually report feeling "under-prepared" and "constrained when approaching and handling certain topics or aspects of discussion, even those merely bordering on controversial (Oulton et al., 2004, p. 489).

The first problem becomes creating clear methods for teaching the elements of controversy and instilling confidence to teach those methods. If knowledge is not seen as morally and politically neutral then, argues Geddis (1991), students need to learn skills that allow them to uncover how particular knowledge claims may serve the interests of different claimants. If they are to be able to take other points of view into account in developing their own positions on issues, they need to attempt to "unravel the interplay of interests that underlie these other points of view" (p. 171). Oulton and colleagues note that when teaching about controversial issues, the challenge is to recognize that issues are controversial, given that protagonists are applying reasoning from their own worldview and thereby may have different positions and perspectives. Students need to explore how it is that individuals can apparently arrive at different perspectives on an issue. Introducing them to multiple perspectives is therefore an essential part of the methods of teaching about controversial issues. As Oulton et al. put it, "The literature on the teaching of controversy includes advice on the principles that teachers might adopt. A number of these principles appear themselves to be controversial: neutrality, balance, and reason" (Oulton et al., 2004, p. 491).

\section{Teacher Training, Attrition and Mentoring}

Teacher education is a highly regulated practice, with each state responsible for developing credentialing systems. In the United States, 1,497 (69\%) of teacher 
preparation and credentialing programs are classified as traditional, $473(22 \%)$ as alternative and situated at institutions of higher learning, and 201 (9\%) as alternative and not situated at institutions of higher learning. Alternatives to traditional four-year undergraduate programs arose as a way to offset teacher shortages and the low numbers of minorities and men entering the profession. Such programs often allow candidates to be the teacher of record in a classroom while simultaneously working to earn their initial credentials (King \& Mahaffie, 2016).

Many teachers drop out of the profession within the first five years. A five-year longitudinal study (2007-08 through 2011-12) found that the percentage of beginner teachers who continued teaching was larger among those who were assigned a first-year mentor than among those who were not. Specifically, the findings were $92 \%$ and $84 \%$ respectively in $2008-09 ; 91 \%$ and $77 \%$ respectively in $2009-10 ; 88 \%$ and $73 \%$ respectively in 2010-11; and $86 \%$ and $71 \%$ respectively in 2011-12 (Gray, Taie, \& O’Rear, 2015). Strong (2006) found that first-year teachers with mentors demonstrated performance gains equivalent to those of fourth-year teachers who did not have the same support.

The practice of mentoring has a long and established history. It is often characterized as non-hierarchical coaching, on-the-job experience, and education, training, and performance management (Willems \& Smet, 2007). Within the teaching profession, new teachers benefit when they participate in formal planning and collaboration with other teachers (Ingersoll \& Smith, 2004; Ingersoll \& Strong, 2011). Willems and Smet (2007) assert that "mentoring is not about bringing in external theories from (expensive) consultants, but about sharing knowledge that has been built from within, tailor-made to the history, challenges, people, and culture of the organization" (p. 108).

Across a wide range of settings, mentoring has been shown to revive enthusiasm (Clutterbuck, 2008), increase self-esteem and self-confidence (Tracy, Jagsi, Starr, \& Tarbell, 2004), and provide psychological support for individuals (Kram, 1985) who may be dealing with role ambiguity, organizational politics, and work-related uncertainty (Viator, 2001). However, typically this form of mentorship pairs an individual with a coworker or peer. While exemplary teachers rank mentoring as the most important factor in their success (Behrstock-Sherratt, Bassett, Olson \& Jacques, 2014), only $28 \%$ of teacher preparation programs require that the advising teachers receive mentorship training - and even fewer programs $(11 \%)$ require that the advising teachers to be effective at raising student achievement (Greenberg, McKee, \& Walsh, 2013). Conclusive research confirms that teachers benefit from mentorship (Bassett et al., 2013; Natale, Bassett, Gaddis, \& McKnight, 2013). Greenberg et al. (2013) further state, "Such opportunities should span the career continuum, with access to teacher leaders through preparation coursework and clinical experiences, mentorship programs, and ongoing professional learning activities" (p. 23).

New forms of mentoring are emerging. One type, called reverse mentoring, involves having an emerging professional advise an established professional. Often the mentor brings a new skillset or knowledge that can benefit the mentee. While seasoned professionals can find technological innovations bewildering and disruptive, the millennial generation was raised with advanced technology and tends to embrace its rapid change (Leh, 2005). These "digital natives" value happiness, passion, diversity, sharing, and discovery and are rising to assume a dominant place in the global workforce.

With the rapid diffusion of educational technology into schools, numerous studies confirm the educational benefits of integrating technology into classrooms (Balanskat, Blamire, \& Kefala, 2006; Organization for Economic Co-operation and Development, 2006, 2010). But research also suggests that many teachers do not make effective use of technology in their classrooms (Hixon \& Buckenmeyer, 2009; Levin \& Wadmany, 2008). Arguably, of more importance is teaching students media literacy, which prepares them to become proficient accessors, analyzers, evaluators, and communicators of information. Media literacy's emphasis is on empowering students to be critical thinkers and creative producers (National Association for Media Literacy Education, 2015). Media literacy significantly improves reading comprehension, critical analysis, and related academic skills (Hobbs, 2007), catalyzes motivation, and teaches capable citizenship (Madison, 2012, 2015).

Millennials who have recently earned a college degree in journalism possess competencies in both media literacy and citizenship education and they represent an untapped resource for facilitating educational reform. Several educator training programs such as Teach for America actively recruit millennials and place them in underserved communities. However, these new educators frequently find themselves working as lone rangers in unfamiliar settings, serving as the sole teacher-of-record, and these programs' attrition rates are 
high (Donaldson \& Johnson, 2011). Conversely, the reverse mentorship strategy studied here places millennials alongside career educators to enhance, rather than replace, teachers, and it seeks to broaden students' learning experiences.

Examples of reverse mentorship in education are scarce, and when they occur it is generally at the college level. Collaborations between young working professionals and professors have been forged to bridge the gap between real-world innovation and academia (Leh, 2005). Arman and Scherer (2002) studied the efficacy of reverse mentorship by assigning student mentors to professors for service learning projects. Morgan and Streb (2001) examined students who were tasked with mentoring elderly participants in a computer skills course. Numerous other studies suggest that reverse mentoring supports learning in a social context (Bennett \& Green, 2001; Carr, 2002; Clark, 2002; Solomon, 2001). This approach is grounded in constructivist theories most often associated with Dewey (1938) and Vygotsky (1987), which privilege social interaction, reflection, and experience.

\section{Situated Learning and Communities of Practice}

Situated learning, a theoretical construct that views practice as learning, frames this case study. Situated learning is immersive and social. It occurs within communities of practice where collaborators with varying levels of competency form, perpetuate, and negotiate identities - as well as make meaning together (Lave \& Wenger, 1991; Wenger, 1998). The theorists posit that situated learning thrives in spaces where "learning and its application takes place in the same location" (Brown, 2014, p. 1). In teacher education, jobembedded professional development (JEPD) is aligned with this theory and has been part of academic research since the late 1990s, with more targeted research starting in the last half-decade (Desimone, 2011).

Experience-based professional development of teachers is not new. However, in a time of increasing technology and decreasing budgets, many schools' professional development efforts are moving away from situated learning. Darling-Hammond and McLaughlin (1995) assert, “The nation's reform agenda require(s) most teachers to rethink their own practice, to construct new classroom roles and expectations about student outcomes, and to teach in ways they have never taught before - and probably never experienced as students" (p. 81). Desimone (2011) argues that JEPD "best practices" challenge teachers to share responsibility for their own professional development learning outcomes, and that they should include at least 20 hours per semester of contact time. Real-time JEPD occurs in the classroom as students are learning, and focuses on the actual practice of skills for both the teacher and student (Croft, Coggshall, Dolan, \& Powers, 2010).

To build upon this scholarship, the following research questions are posed:

RQ1: What are potential benefits from pairing recent journalism school graduates and secondary educators to advance student learning and the teaching of media literacy?

RQ2: How can educators effectively engage middle school students in explorations of controversial topics?

\section{METHOD}

\section{Case Studies and Field Observation}

Contemporary case study research has roots in anthropology, sociology, and psychology (Merriam, 1988; Merriam \& Tisdell, 2016). Yin (2003) describes case study as an investigative process. "A case study is an empirical inquiry that investigates a contemporary phenomenon (the 'case') within its real-life context, especially when the boundaries between phenomenon and context may not be clearly evident" (p. 16). Stake (2005) argues that case studies seek to isolate a single unit of study - the case within a bound system, a specific instance or related range of instances around which there are boundaries. Therefore, a case study can focus on a single person, group, program, community, or institution (Merriam \& Tisdell, 2016). Case studies can also draw longitudinal comparisons about the same subject or subjects over a defined period of time (Dittrich, 2014; Slaughter-Defoe \& Rubin, 2001).

Use of case studies in journalism and education research is ubiquitous (Brennen, 2013; Merriam, 1988). Borrowing from anthropology and ethnographic work, case studies are deeply descriptive (Geertz, 1994), giving the reader a detailed sense of the setting and subjects. Miles, Huberman, and Saldaña (2014) assert that looking at a case longitudinally "strengthens the validity and stability of the findings" (p. 33). Interviews are integral to the data collection process, and typically involve one-on-one questioning (Merriam, 1988). Qualitative research interviews are commonly openended and unstructured (Merriam \& Tisdell, 2016).

Triangulation in qualitative research strengthens internal validity by providing a minimum of three types 
of data collection. In most case studies, data include interviews, observations, and physical items (Denzin, 1970). Patton (2015) states that "triangulation, in whatever form, increases credibility and quality by countering the concern (or accusation) that a study's findings are simply an artifact of a single method, a single source, or single investigator's blinders" (p. 674).

\section{The Case}

This study examines a pilot program that placed a 25-year-old journalism school graduate at a rural middle school in Western Oregon for a complete nine-month academic year. Orchard Middle School (a pseudonym) is located in a rural western Oregon farming community with approximately 6000 residents. Its five-block main street features familiar fast-food brands, a car dealership, and several thrift shops - under the shadow of a water tower. In the 2010 census the town's racial makeup was $90.4 \%$ White, 9\% Hispanic or Latino, $0.7 \%$ African American, 1.3\% Native American, 0.6\% Asian, $0.1 \%$ Pacific Islander, $3.7 \%$ from other races, and 3.2\% from two or more races (U.S. Census, 2010).

A recent journalism school graduate was assigned to work one day each week alongside a sixth grade English-language arts/social studies teacher with 30 years of teaching experience. The reverse mentoring primarily took the form of real-time co-teaching, with the mentor and mentee sharing instructional duties. Their collaboration also included one-on-one planning and prep sessions.

The teacher volunteered to participate in the research team's ongoing university-led initiative, which seeks to investigate the efficacy of journalistic approaches to enhancing secondary-level student learning outcomes.

The teacher, Linda Westmore (pseudonym), was a veteran teacher in her 25 th year of career teaching at Orchard, and 30th year of teaching in total. She manages two sections of a double-block of sixth grade EnglishLanguage Arts and social studies each day. Westmore studied journalism in college, but never practiced it professionally and stated that she was eager to expose her students to journalistic forms of writing. Her young students displayed a "scrappy" and resilient sensibility that allowed them to face the economic challenges their families encounter due to multiple recessions, economic uncertainty, and a sluggish timber industry.

Jacob Thompson (pseudonym), a 25-year-old journalism school graduate, was assigned to work with Westmore and her students every Thursday during the 2016-17 academic year. During his college years, he served in editorial management positions on several student publications, and he is now in his fifth year of counseling students at a California-based journalism summer camp in Palo Alto.

The research team's journalism education initiative seeks to develop, pilot, and test the efficacy of journalism-based programmatic interventions in K-12 education, before scaling them further. These methodologies are intentionally aligned with the Common Core State Standards, which call for $70 \%$ of texts that students encounter in school to be nonfiction by the 12th grade (Common Core State Standards, 2010). The research team drew from both journalism and education institutional affiliations, and included three doctoral students, one master's student, and several undergraduates. This research is supported by donor funding.

Throughout the 2016-17 academic year, the researcher observed approximately 20 onsite course sessions, accompanied by a videographer who documented classroom interactions. Eight separate oncamera interviews were conducted with the mentor, and separately with the teacher, all of which were transcribed. Additionally, the mentor's and teacher's notes and lesson plans were examined, as were studentproduced work samples and publications. The researcher coded his field notes, video footage logs, and interview transcripts to distinguish common themes. Gathered data were cross-referenced to ascertain a more holistic view throughout the program's progression. The study followed IRB approved protocols. Teachers, administrators, parents, and students consented to the videotaping and disclosure of their identities. However, this study uses pseudonyms to identify the schools, mentor, teachers, and students, given the broader dissemination of this research. The researcher and his team acknowledge their positionality in this study, given that it can serve to validate their intended outcomes. To address and mitigate this matter, the project contracted with the Educational Policy Improvement Center (EPIC) (recently renamed Inflexion), a nonprofit independent evaluation and consulting firm that collected data and reported separately.

The following findings discuss some of the postelection controversies that arose during the pilot year, and how the teacher, journalist/mentor, and school administrators collaborated, using the JLI Core Framework, to recast these controversies as "teachable moments." Findings are organized within the context of the two research questions. 


\section{FINDINGS}

Orchard Middle School is a functional single-story building that appears to have received very few updates since it opened in 1977. Windowless hallways are brightened by student art and murals, leading to a central open library; one side is lined with older model desktop computers.

Administrators note that Orchard students' families generally identify as conservative. Several incidents occurred on campus that capture the zeitgeist of the student energy immediately before and after the 2016 presidential election. Leading up to election day, some students proudly displayed "Make America Great Again" Trump stickers affixed to their school binders and lockers. The day after Trump won, another group of students were observed chanting "build the wall, build the wall."

Eric Mathison (pseudonym), the school's principal, intervened when a student was seen passing out mock deportation papers to fellow students who were brownskinned as they entered the school building. He addressed the matter by visiting each class and making personal appeals that stressed the value of inclusiveness and sensitivity to cultural differences.

An inherent risk in implementing a journalism-based program is that it can engage students in educational explorations that may lead them to question beliefs and ideological perspectives learned at home, potentially upsetting parents. While Orchard's administrators and staff did not intend to stir controversy they also did not choose to ignore it. Mathison observed that sixth grade students are starting to think about their beliefs, identity, character and values. He said, "I think sixth grade is a really unique year to start introducing them to some of the regional, national and global issues that we're facing." Mathison acknowledged the value of cultivating student voice and agency, recognizing that "it is a time that kids can start exploring some of those issues" for themselves.

Clear themes emerged from the data regarding the potential minefields that can be associated with teaching controversial subject matter. Thompson, the journalist/mentor assigned to work with Westmore, noted how they carefully collaborated to avoid potential minefields, explaining:

[What] we really wanted to do is give students tools to discuss real issues, particularly in this year when there are a lot of conversations being had about fake news and fake media. How do you tell what is a credible story and a credible source? That was kind of tricky, in the sense that we really couldn't politicize it, even if it was currently in the media. We're working in a fairly conservative community. A lot of the students come from families that voted for Trump.

Thompson and Westmore reinforced appropriate classroom discourse by modeling how a teacher and a recently trained journalist work together in real time, even when they are managing discussion of tough topics. They demonstrated respectful collaboration, mutual flexibility, and on-the-spot learning.

Westmore noted, 'I'm learning from Jacob, and he's learning from me, so we are a learning community together. It's been nice to have [him] here just to kind of bounce ideas off of." She pointed out the value of having access to another adult in the room for validation and feedback, noting,

It's also been nice to have him here to say, "Hey, that went really well," because I think sometimes we get lost in the world of teaching because there's so much to do and there's constantly another conversation to be had.

Addressing RQ1, regarding benefits, student learning, and the teaching of media literacy, the reverse mentorship approach countered adversarial human interactions commonly portrayed in popular media. Thompson and Westmore's exchanges differed sharply from the insult humor that often colors teen-targeted media (Russo, 2014). The "reality" genre perpetuates caustic and overly simplistic solutions to human dilemmas, where people are easily "fired" or jettisoned without remorse or introspection. Except for perhaps parental role modeling, it is unlikely that many middle school-age students have opportunities to witness adults collaborating respectfully.

A vital element of JLI's pedagogical approach centers on Interview Day, a virtual press conference where the class video-conferences with experts about their selected topics. For the first trimester students were placed in teams and encouraged to choose topics aligned with their intrinsic interests, which included robotics, game design, dance, and athletics. For the second trimester, students were asked to identify interests that aligned with social justice themes. Among the chosen topics were animal cruelty, racism, veterans' rights, and the accessibility concerns of disabled people.

One team chose homelessness, and interviewed the executive director of a nonprofit that provides shelter for community members in need. During the course of their exchange, a student named Taylor (pseudonym) said, "I believe homeless people are irresponsible. If they made better choices they would have different lives." Their 
interview guest pointed out that her agency increasingly serves minors who find themselves homeless at no fault of their own. Taylor acknowledged that the exchange opened his eyes to an aspect of homelessness he had not previously considered.

Westmore reflected on the encounter:

Kids have strong feelings about world issues. I think as a teacher and as a society we haven't been trained how to disagree respectfully. So, before we can actually write about things we need to have some standards in place for oral discourse.

In this instance, she and Thompson became aware of Taylor's strong beliefs during an earlier prep session, and anticipated that tension might emerge. Rather than suppress his sentiments, they worked with him in advance to conceive an appropriate and respectful way to express them. The additional coaching achieved the intended outcome.

Thompson and Westmore anticipated and mitigated other potential upsets by closely observing and guiding student work groups as they prepared. They honored students' perspectives, even when those views were out of sync with the teachers' own, trusting students to discover fresh perspectives through the journalistic, investigative discovery. Taylor's revelation about how young people can experience homelessness exemplified that process.

Addressing RQ2, how educators can effectively engage students in explorations of controversial topics, JLI's use of video conferencing platforms opened classrooms to perspectives outside the limited purview of their own communities. Students researched topics, identified experts, and then heard first-person accounts that were validated by lived experiences. While personal use of video conferencing has become somewhat ubiquitous through FaceTime, Skype, Google Hangouts, and similar services, its pedagogical potential remains largely untapped in K-12 education.

On Interview Day, students also took notes and drafted articles about their encounters with guests, which were then published to the web. They learned to synthesize information, organize ideas, and distinguish facts from opinions. This stage of the process speaks to the JLI Framework's emphasis on publication and reflection.

When students share their findings with an authentic audience, and not just their teacher, it validates the worthiness of their effort beyond simply earning a grade. Their community's feedback sparks opportunities for the class to reflect on the impact of their voice and agency, and publication, thereby providing students with a sense of completion.

The Framework supports students in learning that words matter, and that unsubstantiated assertions can have consequences. Principal Mathison spoke about the importance of teaching students to understand biases:

I think [teaching students] what is bias in an article or in writing, is a key component to helping sixth graders understand perspective. [Distinguishing] what is argumentative or informative. And I think that for sixth graders to grasp those concepts is really important. [...] The program has done a nice job of presenting that material without being controversial or introducing things that parents might have concern about.

However, the question arises about whether there are certain issues that educators should completely avoid. What happens if students express interest in writing about contentious subjects such as evolution or climate change?

Thompson addressed this issue:

It's a lot of removing yourself and your own political beliefs. You encourage them to explore a variety of credible sources that present multiple points of view. And then support them in making distinctions about what defines a credible source. Does the source have a track record of being reliable? Or is there a consensus of agreement within the community of bona fide experts?

However, which sources are considered legitimate can also be contentious subject. What if students want to cite CNN versus MSNBC versus Fox News? Thompson observed:

\footnotetext{
It's a matter of helping students make a distinction between commentators and newscasters. Sean Hannity and Rachel Maddow are commentators who overtly express opinions. Conversely, Shep Smith and Anderson Cooper are newscasters. They may appear on the same channels as commentators but the orientation of their work is fundamentally different.
}

Honoring student voice and agency, while simultaneously getting ahead of anticipated controversies and encouraging students to make more appropriate choices when expressing their opinions, emerged as key strategies. Others were encouraging students to engage in self- or group-directed research, and to discern for themselves which sources were credible. And perhaps the most significant strategy was modeling socially appropriate discourse through the teachers' mentorship interactions.

The Educational Policy Improvement Center (EPIC) (recently renamed Inflexion), the organization that assesses the College Board's Advanced Placement 
programs and the International Baccalaureate programs, was contracted by the research team to independently assess the efficacy of the middle and high school level programs. When interviewed, Westmore reflected on its significance. "This journalism program has had me examine my teaching practices, and it really is actually nice sometimes," she said. "As teachers, we're stuck in our own little worlds. I was teaching the kids how to write and I had good instructional practices, but it is very reassuring for me to be talking to [...] colleagues." According to student survey responses, both middle school students $(86.79 \%)$ and high school students $(91.30 \%)$ overwhelmingly agreed that the topics and skills learned continued to be useful and relevant to them" (EPIC, 2017).

\section{CONCLUSIONS}

Crowded classrooms and resource-strapped public schools challenge many educators who are committed to providing students a high quality education. The presence of a second, newly minted professional can bring fresh perspectives to students' classroom experiences. The approach supports teachers through real-time professional development. However, success can rely on several unpredictable variables. Interpersonal chemistry is key. Maturity and collegiality are vital traits for successful reverse mentors who may have limited work experience. Personality and workstyle conflicts are unpredictable and can potentially become acrimonious, given that teachers are typically unionized and less experienced mentors are part-time contractors.

The pilot program benefitted from partnering with a forward-thinking teacher and administrator. The program was not forced upon them, Westmore was a willing participant and Mathison was a supportive principal. Further study is warranted around the efficacy of this work in less accepting circumstances.

Technology could also impede implementation. While she was eager to learn, Westmore had never used Skype, and it was on a list of software arbitrarily banned by the school district. Thompson had to lobby the district's Internet Technology office to gain a waiver. Failure to win a reprieve would have thwarted the potential of Interview Day.

Related logistics were also challenging, as the instructional team worked to support their sixth graders in scheduling guests. It required lots of off-hours phone calls, emailing, and patience, given there were 14 interview subjects to arrange between the two sections of the class.

As the programs expands in terms of mentors, lack of consistency and high costs could become impediments. Recent journalism school graduates do not command the salaries of more seasoned professionals. However, the costs can become prohibitive as the program endeavors to serve more schools. Also, parttime employment, shortly after earning a degree, may have short-term appeal for recent college graduates whose interest in teaching can be secondary to launching a fulltime journalism career. This could lead to high turnover, adversely affecting consistency.

Additionally, the current program relies solely on donor support, which can be unpredictable at best. It would benefit from transitioning to a fee-based model, supported by school districts and public funds. Such a transition requires establishing more of a track record and credibility. It may also entail developing a sales infrastructure, which has its own set of costs.

While the researchers acknowledge the value of inperson reverse mentoring, further research will explore the efficacy of a hybrid approach to implementation that preserves but reduces the in-class mentoring contact hours, and supplements it with online video training and webinars. This model will begin with onsite consulting and transition to online support of teachers who would form professional learning communities (PLCs) within their schools or school districts. This will require close monitoring to insure the program maintains the high level of relatedness that comes from face-to-face mentoring. A key question will be how much in-person mentoring is needed to establish a sufficient foundation before transitioning to a blended online approach. It is possible that periodic in-person coaching can reinforce the online support. Prerequisites for scaling this modification of the program will include establishing protocols, effective training, quality controls, and ongoing support.

Despite ideological divides, educators have an obligation to engage students in subjects that challenge them to think. Teaching students to engage in critical thinking is often touted as a pedagogical ideal. Yet the term is so overused, it arguably has been rendered meaningless. I prefer the term informed thinking, which has been adopted by the Maine Department of Education, to more specifically describe a deeper level of student engagement, one that our research indicates can better prepare young people to effectively navigate a more complex and nuanced world. Informed thinkers are more than savvy consumers. They become effective 
problem solvers, emerge as content creators, and learn to advocate for public good.

Informed thinking is necessary for makers of media who are willing to actively advocate for change in a democratic society. This is especially true in an evershifting digital landscape, and during times of evergrowing political divide. Educators benefit by teaching students to focus on making distinctions about credible and reliable sources, rather than getting mired in baseless debates that are not tied to sound evidence. Yet becoming an informed thinker requires exposure to diverse perspectives and new positions. Learning to challenge one's preconceived notions is a healthy way to engage with new ideas and to expand one's understanding of complex issues. The classroom becomes an appropriate setting for respectfully exploring a wide range of perspectives. This helps students discern the difference between facts and fabrications. A healthy democracy necessitates the development of informed thinkers as falsified stories become ever more prevalent in media.

\section{FUNDING ACKNOWLEDGEMENT}

This research was supported by donor-funding from Nancy and Dave Petrone, Tara Lynda Guber, and the Anne Wojcicki Foundation.

\section{REFERENCES}

Arman, J. F., \& Scherer, D. (2002). Service learning in school counselor preparation: A qualitative analysis. The Journal of Humanistic Counseling, Education and Development, 41(1), 69-86.

Balanskat, A., Blamire, R., \& Kefala, S. (2006). The ICT impact report: A review of studies of ICT impact on schools in Europe. European Communities. Retrieved from

http://unpan1.un.org/intradoc/groups/public/docume nts/unpan/unpan037334.pdf

Bassett, K., Grossman, T., Allan, P., Allen, M., Cook, S., \& Olney, J. (2013). Reimagining teaching: Five structures to transform the profession [White Paper]. Arlington, VA: National Network of State Teachers of the Year. Retrieved from http://www.nnstoy.org/download/Various/ White\%20Paper\%2010-4-2013\%282\%29.pdf

Behrstock-Sherratt, E., Bassett, K., Olson, D. \& Jacques, C. (2014). From good to great: Exemplary teachers share perspectives on increasing teacher effectiveness across the career continuum.
Washington, DC: Center of Great Teachers and Leaders.

Bennett, G., \& Green, F. P. (2001). Promoting service learning via online instruction. College Student Journal, p. 491. Retrieved from digitalcommons.unomaha.edu/slcehighered/20/

Blinn, J. R. (1982). A comparison of selected writing skills of high school journalism and non-journalism students. (Doctoral dissertation). Ohio University, Athens, OH. Available from ProQuest Dissertations \& Theses A\&I. (303244941).

Brennen, B. (2013). Qualitative research methods for media studies. New York, NY: Routledge.

Brown, T. (2013). T10 Situated Learning Theory of Lave and Wenger. Available at documents.routledgeinteractive.s3.amazonaws.com/ 9780415829496, p. 10.

Carr, K. (2002). Building bridges and crossing borders: Using service learning to overcome cultural barriers to collaboration between science and education departments. School Science and Mathematics, 102(6), 285-298.

Clark, C. T. (2002). Unfolding narratives of service learning: Reflections on teaching, literacy, and positioning in service relationships. Journal of Adolescent \& Adult Literacy, 46(4), 288-297.

Clutterbuck, D. (2008). Mentoring and retention. Clutterbuck Associates Newsletter, August 2008.

Common Core State Standards Initiative (CCSS). (2010). English language arts standards: Introduction - Key considerations. Available at http://www.corestandards.org/ELALiteracy/introduction/key-design-consideration/

Croft, A., Coggshall, J. G., Dolan, M., \& Powers, E. (2010). Job-embedded professional development: What it is, who is responsible, and how to get it done well. Issue Brief. National Comprehensive Center for Teacher Quality. Available at https://learningforward.org/wpcontent/uploads/2017/08/job-embeddedprofessional-development.pdf

Darling-Hammond, L., \& McLaughlin, M. W. (1995). Policies that support professional development in an era of reform. Phi Delta Kappan, 76(8), p. 597.

Denzin, N.K. (1970). The research act: A theoretical introduction to sociological methods. Chicago, IL: Aldine.

Desimone, L. M. (2011). A primer on effective professional development. Phi Delta Kappan, 92(6), 68-71. 
Dewey, J. (1938). Experience and education. New York, NY: Macmillan.

Dittrich, Ellen. (2014). Underachievement leading to downgrading at the highest level of secondary education in the Netherlands: A longitudinal case study. Roeper Review, 36(2), 104-113.

Donaldson, M. L., \& Johnson, S. M. (2011). Teach For America teachers: How long do they teach? Why do they leave? Phi Delta Kappan, 93(2), 47-51.

Dvorak, J. (1988). High school publications experience as a factor in college-level writing, Journalism Quarterly, 65(2), 392-98.

Dvorak, J., Bowen, C. P., \& Choi, C. (2009). Minority journalism student academic comparisons between those with and those without high school print media experience. Journalism \& Mass Communication Educator, 64(3), 258-272.

Dvorak, J., \& Choi, C. (2009). High school journalism, academic performance correlate. Newspaper Research Journal, 30(3), 75-89.

Educational Policy Improvement Center. (2017). A developmental evaluation of the Journalistic Learning Initiative Pilot. Educational Policy Improvement Center.

Geddis, A. (1991). Improving the quality of science classroom discourse on controversial issues. Science Education, 75(2), 169-183.

Geertz, C. (1994). Thick description: Toward an interpretive theory of culture. In M. Martin \& L. C. McIntyre (Eds.), Readings in the Philosophy of Social Science (pp. 213-231). Cambridge, MA: MIT Press.

Gray, L., Taie, S., \& O'Rear, I. (2015). Public school teacher attrition and mobility in the first five years. Retrieved from U.S. Department of Education website: http://nces.ed.gov/pubs2015/2015337.pdf

Greenberg, J., McKee, A., \& Walsh, K. (2013). Teacher prep review: A review of the nation's teacher preparation programs. Washington, DC: National Council on Teacher Quality. Retrieved from http://www.nctq.org/dmsView/Teacher_Prep_Revie w_2013_Report

Hixon, E. and Buckenmeyer, J. (2009). Revisiting technology integration in schools: Implications for professional development. Computers in the Schools, 26(2), 130-146

Hobbs, R. (2007). Reading the media: Media literacy in high school English. New York, NY: Teachers College Press.
Ingersoll, R. M., \& Smith, T. M. (2004). Do teacher induction and mentoring matter? National Association of Secondary School Principals Bulletin, 88 (638), 28-40.

Ingersoll, R. M., \& Strong, M. (2011). The impact of induction and mentoring programs for beginning teachers: A critical review of the research. Review of Educational Research, 81(2), 201-233.

Kerr, D., Lines, A., Blenkinsop, S. \& Schagen, I. (2003). Citizenship and education al age 14: A summary of the international findings and preliminary results for England. Slough: National Foundation for Educational Research and London: Department for Education and Employment.

King, J., \& Mahaffie, L. (2016). Preparing and credentialing the nation's teachers: The Secretary's tenth report on teacher quality. Washington, D.C.: U.S. Department of Education.

Kram, K. E. (1985). Mentoring at work. Lanham, MD: University Press of America.

Lave, J., \& Wenger, E. (1991). Situated learning: Legitimate peripheral participation. Cambridge, U.K.: Cambridge University Press.

Leh, A (2005). Lessons learned from service learning and reverse mentor. Journal of Technology and Teacher Education, 13(1), 25.

Levin, T. and Wadmany, R. (2008). Teachers' views on factors affecting effective integration of information technology in the classroom: Developmental scenery. Journal of Technology and Teacher Education, 16(2), 233-263

Madison, E. (2012). Journalistic Learning: Rethinking and redefining language arts curricula (Doctoral dissertation). University of Oregon, Eugene, OR. Available from ProQuest Dissertations \& Theses A\&I. (1237275104).

Madison, E. (2015). Newsworthy: Cultivating critical thinkers, readers, and writers in language arts classrooms. New York, NY: Teachers College Press.

Merriam, S. (1988). Case study research in education: A qualitative approach (1st ed., Jossey-Bass education series). San Francisco: Jossey-Bass.

Merriam, S., \& Tisdell, E. J. (2016). Qualitative research: A guide to design and implementation (4th ed.). San Francisco, CA: Jossey-Bass.

Miles, M., Huberman, A. M, \& Saldaña, J. (2014). Qualitative data analysis: A methods sourcebook (3rd ed.). Thousand Oaks, CA: SAGE Publications. 
Morgan, W., \& Streb, M. (2001). Building citizenship: How student voice inservice learning develops civic values. Social Science Quarterly, 82(1), 156-169.

Morrell, E. (2004). Linking literacy and popular culture: Finding connections for lifelong learning. Norwood, MA: Christopher-Gordon.

National Association for Media Literacy Education. (2015). Media literary defined. Retrieved from namle.net/publications/media-literacy-definitions/

Natale, C. F., Bassett, K., Gaddis, L., McKnight, K. (2013). Creating sustainable teacher career pathways: A 21st century imperative. Washington, DC: National Network of State Teachers of the Year \& Pearson Research and Innovation Network. Retrieved from www.nnstoy.org/download/Various/CSTCP_21CI_ pk_final_web.pdf

Organization for Economic Co-operation and Development. (2005). Are students ready for a technology-rich world? What PISA studies tell us. Paris: OECD Publications. Retrieved from www.oecd.org/education/school/programmeforinter nationalstudentassessmentpisa/35995145.pdf

Organization for Economic Co-operation and Development. (2010). Are the new millennium learners making the grade? Technology use and educational performance in PISA 2006. Paris: Centre for Educational Research and Innovation, OECD Publishing.

Oulton, C., Day V., Dillon, J., and Grace, M. (2004). Controversial issues - teachers' attitudes and practices in the context of citizenship education. 30(4), 489-507 Oxford Review of Education.

Patton, M. (2015). Qualitative evaluation and research methods (4th ed.). Newbury Park, Calif.: Sage Publications.

Russo, C. E. (2014). The insidious sitcom: Features of tween TV that increase tolerance of verbal insults (Doctoral dissertation). Vanderbilt University, Nashville, TN.

Slaughter-Defoe, D., \& Rubin, H. (2001). A longitudinal case study of Head Start eligible children: Implications for urban education. Educational Psychologist, 36(1), 31-44.

Solomon, M. (January 29, 2001) Coaching the boss. Computerworld. Retrieved from http://www.computerworld.com/article/2590381/itcareers/coaching---the-boss.html

Stake, R.E. (2005) Qualitative case studies. In N. Denzin \& Y. S. Lincoln (Eds.). The Sage handbook of qualitative research (3rd ed.). Thousand Oaks, CA: Sage Publications.

Steimle, J. (May 4, 2015). Reverse mentoring investing in tomorrow's business strategy. Forbes. Retrieved from https://www.forbes.com/sites/joshsteimle/2015/05/0 5/reverse-mentoring-investing-in-tomorrowsbusiness-strategy/\#409cf36e6769

Stradling, R. (1985) Controversial issues in the curriculum. Bulletin of Environmental Education, (170), 9-13.

Strong, M. (2006). Does new teacher support affect student achievement? (Research brief). Santa Cruz, CA: New Teacher Center. Retrieved from http://www.newteachercenter.org/sites/default/les/n tc/main/resources/BRF_DoesNewTeacherSupportA ffectStudentAchievement.pdf

Tracy, E., Jagsi, R., Starr, R., \& Tarbell, N. (2004). Outcome of pilot faculty mentoring program. American Journal of Obstetrics and Gynecology, 191(16), 1846-1850.

U.S. Census. (2010). American Community Survey. Retrieved from https://www.census.gov/programssurveys/acs/methodology/questionnairearchive.2010.html

Viator, R. E. (2001). The association of formal and informal public accounting mentoring with role stress and related job outcomes. Accounting, Organizations and Society, 26(1), 73-93.

Vygotsky, L. (1987). Thinking and speech (N. Minick, Trans.). In L. S. Vygotsky, Collected works (Vol. 1, pp. 39-285). New York, NY: Plenum.

Wenger, E. (1998). Communities of practice: Learning, meaning, and identity. Cambridge, U.K: Cambridge University Press.

Willems, H., \& Smet, M. (2007). Mentoring driving diversity. Organization Development Journal, 25(2), p. 107.

Yin, R. (2003). Case study research: Design and methods (3rd ed., Applied social research methods series; v. 5). Thousand Oaks, CA: Sage Publications. 